\title{
GEOGRAFÍA DE UN DESPLAZAMIENTO. EL CIRCUITO PERIURBANO EN LOS SIETE LOCOS DE ROBERTO ARLT ${ }^{1}$
}

Geography of a Displacement. The periurban circuit in Los siete locos by Roberto Arlt

Juan D. Cid Hidalgo*

Resumen

La locura en Los siete locos es resultado de un intento de integración a la realidad sufrido por los personajes revolucionarios, a quienes se les adosa ese otro bloque de sentido, aquel en abierta polémica con el logos imperial que expele a los individuos que no se dejan disciplinar. Con esto, entonces, se intensifica en ellos la insurrección y la diferencia con los disciplinados y posibilita la exploración de otros lugares/no-lugares, además de cartografiar "futuros parajes", propicios para la asunción de la nueva sociedad. Los locos de Arlt no son producto de una desadaptación social, sino de una adaptación a las condiciones alienadas de la sociedad bonaerense por la que circulan.

Palabras clave: Loco, Ciudad, Desterritorialización, “Espacios otros”, Heterotopía, Saber, Poder.

\section{Abstract}

Madness in Los siete locos is the result of an attempt of integration into reality that is experienced by revolutionary characters, to whom that other type of sense is added; one which is openly opposed to the imperial logo that expels individuals who do not let themselves to be disciplined. Thus, in these characters there is an intensification of the insurrection and distinction from those who are disciplined. This allows the exploration of other places/nonplaces and also helps to map "future settings" appropriate for the emergence of the new society. Arlt's madmen are not the result of a social mismatch but of an adaptation to the alienated conditions of the Buenos Aires society that they are part of.

Key words: Madman, City, Deterritorialization, “Other spaces”, Heterotopy, Knowledge, Power.

La figura del escritor argentino Roberto Godofredo Christophersen Arlt (19001942) es, sin ninguna duda, una de las más polémicas en la historia de la literatura latinoamericana. Sujeto genial para unos como bárbaro para otros, lo cierto es que la obra que nos ha legado resiste el olvido aunque por la incomprensión de sus contemporáneos casi nos quedamos sin ella ${ }^{2}$.

\footnotetext{
${ }^{1}$ Esta investigación forma parte del proyecto FONDECYT No 3100007: Novela, filantropía y saber. Ficcionalizaciones de la locura en Latinoamérica.

${ }^{2}$ Conocidísimos son los argumentos para rechazar la calidad de las obras de Arlt. Desde que sus textos están mal escritos, en un primitivo y deficitario castellano, hasta su agresividad y dureza en la sistemática construcción de imágenes urbanas que retratan un Buenos Aires lejano al asentado en el mito de la ciudad luz.
} 
Con motivo del centenario de su nacimiento, el Centro Virtual Cervantes (http://cvc.cervantes.es/) recogió en su sitio un cúmulo de trabajos y acercamientos, académicos y sentimentales, respecto de la figura del destacado escritor argentino y la inconmensurable influencia debida a sus textos por la novelística latinoamericana (De Castro y González, 2000; Szmetan, 2000). La indiscutible influencia de sus textos es perceptible hasta en la novelística del boom latinoamericano de los años sesenta, particularmente en la pluma de Julio Cortázar ${ }^{3}$ y del uruguayo Juan Carlos Onetti (1981), además de la notable influencia en la generación de la década siguiente en Argentina, cifrada en Ricardo Piglia — quizá su más alto discípulo y difusor- y Jorge Assis.

Juan Carlos Onetti, quien conoció a Roberto en la década del treinta en la capital argentina ${ }^{4}$, es el que mejor condensa esta fascinación y deslumbramiento por la figura genial del argentino: "No sé si es un ser angélico, un hijo de puta o un farsante, acaso era las tres cosas" (Szmetan, en línea). Con esta desconcertante declaración, pareciera que el mismo Onetti vislumbrara que personalidades como la de Arlt se escapan a la "norma" porque se ven desbordados por sí mismos y porque la "lengua nacional" no da el ancho para verter esos sueños de la razón (productores de monstruos, diría Goya), por lo que se ve obligado a generar una lengua nueva, una "lengua extranjera" que se configura a partir del delirio individual. Leemos en Crítica y clínica:

Así, la literatura presenta ya dos aspectos, en la medida en que lleva a cabo una descomposición o una destrucción de la lengua materna, pero también la invención de una nueva lengua dentro de la lengua mediante la creación de sintaxis. "La única manera de defender la lengua es atacarla... Cada escritor está obligado a hacerse su propia lengua...". Diríase que la lengua es presa de un delirio que la obliga precisamente a salir de sus propios surcos (Deleuze, 16-17).

\footnotetext{
${ }^{3}$ En Roberto Arlt. El torturado (1998), Raúl Larra comenta acerca de esta relación curiosa de admiración y rechazo del escritor de Rayuela hacia Arlt. "Cuentitos a lo Roberto Arlt. Ese menosprecio evidente de Cortázar por Arlt es bien injusto. Sobre todo porque si se rastrea la obra del autor de Rayuela se advertiría la influencia de Arlt. ¿Acaso Cortázar podría haber escrito así con ese desenfado toda la primera parte de Los premios si en la literatura argentina no se hubiese dado un Arlt?" (55). Por lo demás no hay que olvidar que el propio Cortázar redacta el prólogo a las Obras Completas de Roberto Arlt, en el que se puede apreciar esta tensión señalada cuando caracteriza su escritura como la de un "Goya canyengue" o "Villón de quilombo".

${ }^{4}$ En el prólogo a El juguete rabioso leemos: "Tendría entonces unos treinta y cinco años edad, una cabeza bien hecha, pálida y saludable, un mechón de pelo negro duro sobre la frente, una expresión desafiante que no era deliberada, que le había sido impuesta por la infancia, y que ya nunca lo abandonaría" $(1981,10)$.

${ }^{5}$ Gilles Deleuze en Crítica y clínica (1996) nos presta su noción de lengua extranjera para explicar esa particularidad que tienen ciertas escrituras de generarse a sí mismas, de construir una lengua -"asintáctica y agramatical"- distinta a la convencional cuyo fin único y último es la comunicación y no el agenciamiento. En Diálogos (1997), en tanto, agrega: "el escritor es ciertamente aquel que empuja el lenguaje hasta un límite que separa el lenguaje de la animalidad, del grito, del canto".
} 
Esta nueva lengua "tartamuda", anómala, es la que ha definido el ejercicio literario de notables escritores europeos (Proust, Joyce, Kafka), pero también de escritores latinoamericanos (Arlt, Sarduy, Lezama). Hoy es posible comprender el desconcierto provocado por la "manera" de escribir de Roberto Arlt que saca la lengua de los caminos convencionales y la hace delirar con lo que genera una "línea mágica que escapa del sistema dominante" (Deleuze, Crítica y clínica, 16). Los llamados defectos de su escritura son hoy precisamente una de las virtudes del discurso novelesco arltiano. Palabras como "menestrala" y "morcona", o verbos como "soliloqueó" para decir que Remo "pensó", produjeron gran incomodidad en aquellos lectores "tradicionales" y "puristas" que preferían un despliegue barroco y elegante de la lengua.

En otro nivel un buen sector de la crítica ha trabajado una línea de exégesis que ha llamado "escritura de la derrota" (Tassi, 2004) en la narrativa arltiana. Sin embargo, a nuestro modo de ver, esta clasificación solo es pensable si damos por establecido que existe un ganador. Creemos que si existe este binarismo no hace justicia a un ejercicio de reconocimiento de las dimensiones del poder que interactúan en sus textos y que lo instalan como uno de nuestros escritores mayores.

El saber oculto del revolucionario, exhibido por un grupo de locos con "inquietud revolucionaria", descubre que es posible una versión alterna de la realidad experimentada desde el fracaso del disciplinamiento que, en el caso de los locos liberados, constituye una esperanza, una posibilidad de construir un espacio en que su inquietud sea posible sin exclusión. Por lo demás, el escritor argentino se suma a la idea de Artaud en el sentido de que los locos enuncian "verdades insoportables" (Artaud, 77): "A mí, como autor, estos individuos no me son simpáticos. Pero los he tratado. Y todo autor es esclavo de sus personajes, porque ellos llevaban en sí verdades atroces que debían ser conocidas" (Larra, 76).

La extraña y delirante lucidez de estos perturbadores en acción se condice perfectamente con el hábito, formado desde pequeño por Arlt, de escuchar a los "vagos de barrio" (Larra, 145), señales que han quedado marcadas en textos como Los siete locos, Los lanzallamas y El jorobadito, pero particularmente en el primero donde la "víctima" es el hombre: "La vida ha perfeccionado la angustia, como un fabricante perfecciona su motor a explosión", señala Erdosain.

\section{DESPLAZAMIENTOS AL MARGEN. “ENTRE” BUENOS AIRES Y TÉMPERLEY}

Una mirada al desplazamiento de los locos desde el centro metropolitano (Buenos Aires) a la zona periférica (Témperley) podría ser percibida como una forma de "enajenación" (estar/sentirse ajeno), de desterritorializarse para volver a reterritorializarse en un "espacio otro" (Foucault, 1999), alterno al paisaje terrorífico y esperpéntico de la urbe, siguiendo a la intelectual argentina Beatriz Sarlo, en Una modernidad periférica: Buenos Aires 1920-1930 (1988), diríamos que es un "espacio urbano modelado por la pobreza inmigratoria, el bajo fondo y la tecnología. (...) Los 
sueños se construyen con materiales surgidos de paisajes casi futuristas de la ciudad moderna" (58-59). En este sentido, creemos de profundo valor el trabajo de Evelia Romano y Micah Gel-Redman, quienes perciben en la novelística de Roberto Arlt un interés por la proyección de un Buenos Aires futuro ${ }^{6}$. Es en este contexto paradójico en que aparece la figura enorme de Roberto Arlt, quizá quien mejor perpetuó la miseria fantasmagórica del espacio marginal urbano, pero sin quedarse en la mera descripción de la angustia y la soledad moderna sino percibiendo, en ese mismo espacio de oscuridad revitalizada por la repetición de los mismos gestos que perpetúan su condición, que es posible la utopía. Utopía propuesta por un grupo de locos perfectos (siete), a quienes no se les debe tomar en serio porque se encuentran fuera de sus cabales, porque además es impensable una refundación a partir de unos padres de la patria con características tan singulares. Como en Erasmo, los locos de Arlt defienden su saber ante nosotros que percibimos en esta infracción (Pewzner, 1999) la posibilidad del cambio social. "Aquel era otro mundo dentro de la ciudad canalla que él conocía, otro mundo para el que ahora su corazón latía con palpitaciones lentas y pesadas" (Arlt, 26).

El espacio urbano del texto lo descubrimos por medio de la experiencia de los personajes que deambulan, en un permanente estado de reconocimiento, por el territorio en que se confunden el deterioro de las calles sucias y mal olientes con el deterioro interno de sus habitantes: "Hoy la ciudad está enamorada de sus rufianes (...) las ciudades están como las prostitutas, enamoradas de sus rufianes y de sus bandidos" (Arlt, 187-188). Buenos Aires, entonces, es la "ciudad puerca" (158), un organismo vivo (Le Corbusier, 2003) que va generando núcleos y esporas de tal manera que organiza jerárquicamente sus usos y las distintas categorías de ciudadanos. En Buenos Aires de Los siete locos el espacio urbano es estrecho, sofoca, constriñe y disciplina los cuerpos de sus habitantes.

Porque esta angustia llegó a ser tan persistente, que de pronto descubrió que su alma estaba triste por el destino que en la ciudad aguardaba a su cuerpo, un

\footnotetext{
${ }^{6}$ Evelia Romano y Micah Gel-Redman, en "Profecías de entonces, textos de hoy: la ciudad y la narrativa argentina de las primeras y últimas décadas del siglo XX", texto recogido en Revista de Humanidades: Tecnológico de Monterrey, № 8, México, Instituto Tecnológico y de Estudios Superiores de Monterrey (ITESM), 2000, pp. 197-220), realizan una revisión del espacio urbano (Buenos Aires) en tres autores argentinos de suma importancia (Roberto Arlt, Ricardo Piglia y Rodrigo Fresán), investigación con la que constatan que el crecimiento y modernización de la capital argentina a partir de 1910 trae consigo cambios tecnológicos que influenciarán decisivamente el panorama cultural y social de la ciudad. A grosso modo destacan de Arlt la descripción de la ciudad por venir, sus textos se proyectarían insistentemente hacia el futuro, "lo que supone una nueva percepción y concepción de la realidad, y, en consecuencia, implica un nuevo lenguaje para expresarla". "Una opción frente al crecimiento y rápida modernización de Buenos Aires fue el nostálgico refugio en las tradiciones del pasado, representadas mayormente por la sociedad rural. A la hibridación social y cultural que imponen la inmigración, la industrialización y la participación en el mercado mundial, se opone la redefinición de una esencia que se cree escondida en el pasado. Sin embargo, la modernidad de las primeras décadas del siglo trae consigo una irresistible tensión hacia el futuro en el escenario cosmopolita de la ciudad" (Arlt, 198).
} 
cuerpo que pesaba setenta kilos y que él solo veía cuando lo encaminaba frente a un espejo (103-104).

En otro momento el texto agrega:

Lo que hay es que en la ciudad no se puede ser valiente. Usted sabe que si le estropea la cara a un desgraciado los trámites policiales lo van a molestar tanto, que usted prefiere tolerar a hacerse justicia por su mano. Esa es la realidad. Y uno se acostumbra a ser un resignado, a refrenar los impulsos... (163).

El acto de desplazamiento, como vemos, es inminente. Los personajes citadinos inconformes (no con/formados) con la constitución espacial, moral y, en último término, social dada, necesariamente emprenden el viaje ${ }^{7}$. Tres son los espacios novelados principalmente: Buenos Aires y sus barriadas (calles, cafés, prostíbulos, etc.), la quinta de Témperley — propiedad del Astrólogo- (zona rural, aledaña a la ciudad) y la zona industrial entre Buenos Aires y Témperley.

En el capítulo III, titulado "La farsa", encontramos una descripción que se suma a los signos de la ciudad decadente, forma en que se nos aparece la capital argentina

Haffner se levantó, y mirándolo al Buscador de Oro, dijo:

-Ya sabe, compañero; cuando el asunto de la colonia esté listo, me avisa; y si necesita gente, mejor que mejor, yo le proporcionaré una gavilla de malandrines que no van a tener ningún inconveniente en dejar Buenos Aires -y poniéndose el sombrero, sin darle la mano a nadie y saludándolos a todos con un gesto, iba a salir, cuando, recordando algo, exclamó dirigiéndose al Astrólogo-: Si se apura a conseguir el dinero, hay un magnífico prostíbulo en venta. Tiene anexo y churrasquería, y además se juega mucho. El patrón es un uruguayo y pide 15.000 pesos al contado, pero con diez mil y los otros cinco a un año de plazo creo que se conformará (157).

Erdosain a su llegada a la quinta del Astrólogo percibe como sigue ese espacio nuevo, profundamente distinto a la descuidada ciudad capital:

Erdosain pensó:

-Aunque tuviera una barca de plata con velas de oro y remos de marfil, y el océano se volviera de siete colores lisos, y desde la luna una millonaria con las manos me tirara besos, mi tristeza sería la misma... Mas esto no hay que decirlo. Sin embargo, mejor viviría aquí que allí. Aquí podría tener un laboratorio (31).

\footnotetext{
${ }^{7}$ Curioso es el tratamiento arltiano del viaje. En general, lo sabemos con Foucault, los individuos "anormales" son expulsados fuera del centro (y de los textos) por dispositivos generados por las estructuras de poder dominantes para tales efectos. El clásico ejemplo es la nave de los locos. En el caso de la novela de Arlt, son ellos, los "anormales" los que deciden dejar la ciudad para encontrar un lugar otro donde poder territorializarse nuevamente y desde ahí insistir contra la metrópolis, esa ciudad puerca arriba mencionada.
} 
Los personajes arltianos se agencian al territorio, ya sea este Buenos Aires sucio y decrépito, o Témperley, la quinta idílica y tranquila, o la zona entre donde se entrecruzan las intensidades de ambos espacios irreconciliables. Al experimentar el territorio lo reconstruyen en su interior, algún crítico dirá en su alma (Kallinikos, 2002).

Remo Erdosain, ciudadano de Buenos Aires, es un personaje que se autodefine como angustiado: "uno roba, hace macanas porque está angustiado" (Arlt, 37), "la angustia le taponaba la laringe" (Arlt, 15). Su fracaso existencial originado por la pérdida del empleo, por el engaño de su mujer, por la bofetada y la humillación de Barsut, primo de su mujer, da origen a una búsqueda incesante de sentido que lo pueda ayudar a salir del estado mísero a que ha llegado producto de esa falta de adecuación con el engranaje social anterior a su ser. En cierto sentido, la disfunción social que encarna Erdosain demuestra que él fue parte de un proceso fragmentario e inacabado del disciplinamiento similar al que han sido sometidos todos los individuos que conforman ese grupo social y que él, como ser residual, queda sin nada a que aferrarse $^{8}$, razón por la que abraza la inquietud revolucionaria.

$\mathrm{La}$ "inquietud revolucionaria" yo la definiría como un desasosiego colectivo que no se atreve a manifestar sus deseos, todos se sienten alterados, enardecidos, los periódicos fomentan la tormenta y la policía le ayuda deteniendo a inocentes, que por los sufrimientos padecidos se convierten en revolucionarios; todas las mañanas las gentes se despiertan ansiosas de novedades, esperando un atentado más feroz que el anterior y que justifique sus presunciones; las injusticias policiales enardecen los ánimos de los que no las sufrieron, no falta un exaltado que descarga su revólver en el pecho de un polizonte, las organizaciones obreras se revuelven y decretan huelgas, y las palabras revolución y bolcheviquismo infiltran en todas partes el espanto y la esperanza. Ahora bien, cuando numerosas bombas hayan estallado por los rincones de la ciudad y las proclamas sean leídas y la inquietud revolucionaria esté madura, entonces intervendremos nosotros, los militares... (148).

Con la aparición de la inquietud revolucionaria, Remo dará paso a la formación de la Sociedad Secreta, "algo admirable y sencillo" (Arlt, 148), para combatir, reconstruir y refinar la deteriorada sociedad bonaerense. No sabe que tal reconstrucción es imposible porque el aparato social es "molar" (Deleuze) y, por lo tanto, no permite mutaciones, ni cambios, ni metamorfosis. Su razón de ser es la contraria, estratificar, delimitar, estatizar. Deleuze diría "estriar" (Mil mesetas).

Los perturbadores se sienten capaces de alisar el espacio social, deteriorado e inhumano que conocen, de tal manera que las intensidades puedan fluir libremente: "¿Qué harían las fábricas, las casas de modas, los mil mecanismos parasitarios de la ciudad si los hombres se fueran al desierto... si cada uno de ellos levantara su tienda

\footnotetext{
${ }^{8}$ Noé Jitrik, en "Presencia y vigencia de Roberto Arlt" texto recogido en La vibración del presente (1987), propone que los personajes de Los siete locos son "representantes no de tipos de los que salen sino de una instancia histórica que podríamos designar como 'la crisis' (119).
} 
allá abajo? ¿Comprende usted ahora por qué estoy con el Astrólogo? Nosotros los jóvenes crearemos la vida nueva; sí, nosotros" (Arlt, 161-162).

Hacia el final de la novela, Erdosain se convence absolutamente de la necesidad de la revolución y de apoderarse del centro.

De un encontronazo un faquín lo arrojó contra un muro. Erdosain se detuvo espantado, apretó el dinero convulsivamente en su bolsillo, y excitado, ferozmente alegre como un tigrecito suelto en un bosque de ladrillo, escupió a la fachada de una casa de modas, diciendo:

- Serás nuestra, ciudad (252).

Como podemos apreciar, la estancia de Remo en Buenos Aires se encuentra profundamente asociada al sufrimiento y la angustia, efectos de esa opresión que la ciudad aplica a los rostros de la diferencia. El panorama cambia radicalmente cuando se desplaza a la quinta de Témperley, espacio idílico en contraste con la urbe colmada de esperpentos y espacios deteriorados donde habitan seres despreciables. Una descripción casi pictórica de la quinta denota la calidez percibida por Erdosain: "afuera ondulaban los caminos, iluminados por el sol, y el peso de los pájaros doblaban las ramas de los granados, consteladas de asteriscos escarlatas" (38).

Témperley es el lugar de la utopía donde podría cifrarse el "principio esperanza" (Bloch, 2004). En este lugar es posible la felicidad, por consiguiente, es el paisaje ideal para elaborar planes de reconversión social. El desplazamiento, la salida del centro bonaerense en sí mismo ofrece una línea de cambio real objetivo. Reconocemos aquí, junto a Stasys Gostautas (1972), que la felicidad del hombre y de la humanidad toda depende de cómo se resuelva el "problema" de la ciudad, espacio antinatural del hombre.

Expuestos los dos primeros territorios nos corresponde ahora pensar el tercer espacio $^{9}$ o territorio novelado sin nombre que se encuentra a medio camino entre Buenos Aires, la ciudad canalla cuyos habitantes son rufianes y prostitutas, y Témperley ${ }^{10}$, la zona campestre idílica "donde se salvan las almas que enfermó la civilización” (Arlt, 161). Esta zona fronteriza periurbana ${ }^{11}$, comienzo y fin de las otras

\footnotetext{
${ }^{9}$ No confundir con la noción acuñada por Alberto Moreiras (1999), en que el crítico poscolonial reflexiona sobre esta "localización intermedia latinoamericana, es decir, un tercer espacio ni realmente metropolitano ni realmente periférico construido, en términos estrictamente simbólicos, por la escritura antiontológica del continente" (Moreiras, 1999, 21), utilizando como herramienta el concepto punctum barthesiano. De todas maneras, recomendamos la lectura de Roberto Arlt: El quinto fantoche (Chile, Universidad de Chile, 2003. Disponible en:

http:/www.cybertesis.cl/tesis/uchile/2003/torres_m/html/index-frames.html), tesis de grado de María Torres Valenzuela que se hace cargo de la idea de tercer espacio y del aparataje teórico correspondiente para acercarse a la escritura arltiana.

${ }^{10}$ Hacemos notar que desconocemos alguna aproximación a la tensión entre civilización y barbarie en Los siete locos, que bien pudiera ser una línea de ingreso interesante de abordar en otra oportunidad.

${ }^{11}$ Concepto utilizado en la descripción geográfica para designar una franja que se encuentra alrededor de las ciudades, franja de carácter rural donde la influencia urbana es mayor por su inmediatez física a la
} 
dos zonas, es un lugar dominado por las aplicaciones técnicas de cables telefónicos, durmientes y vías de ferrocarril, estructuras metálicas, carteles de publicidad, etc. Las formas arquitectónicas definidas, aunque esperpénticas y descoloridas, dan paso a un espacio con nuevas exigencias que a la arquitectura simple y dispuesta de la modernidad no puede satisfacer. Esta metamorfosis de la modernidad implica transición y creemos que este espacio transitorio cifra el proceso de metamorfosis de un mundo de seguridades a uno de incertidumbres, donde la técnica exacerba esta condición porque el componente humano, demasiado humano, queda relegado a un lugar de menor prestancia:

El paisaje tecnológico y justamente el factory-slum están muy presentes en la novela doble de Roberto Arlt. El colapso de las formas al servicio de la funcionalidad mecánica y tecnológica y la aparición de construcciones gigantescas en obras caracterizan no solamente la periferia urbana sino que invaden hasta el núcleo de la ciudad, introduciendo rupturas en la textura de la ciudad moderna industrial, modelo al que se aproxima el Buenos Aires arltiano (Kallinikos, 252).

Este espacio desconocido por los ciudadanos de Buenos Aires desborda la zona periurbana y la erige como un mundo aparte - un no lugar-, un microcosmos vedado a quienes solo deambulan por el centro, por las "solitarias ochavas de las calles Arenales y Talcahuano, por las esquinas de Charcas y Rodríguez Peña, en los cruces de Montevideo y Avenida Quintana, apeteciendo el espectáculo de esas calles magníficas en arquitectura, y negadas para siempre a los desdichados" (Arlt, 26) ${ }^{12}$.

El mundo arltiano exhibido en la novela va cartografiando "futuros parajes" (Deleuze y Guattari, 2000). El desastre exterior se introduce mediante el conocimiento y descubrimiento de los nuevos lugares por parte de los personajes, estos repiten el caos exterior en su ser. De esta manera, entonces, los personajes experimentan la realidad que, a su vez, va reproduciendo en ellos la angustia y el terror (Mandakovic, 1978), que transitan mutuamente entre los territorios exteriores colectivos y el territorio interior particular. Con esta tensión y recíproco intercambio de intensidades aparecen esas imágenes distorsionadas y delirantes tan propias de la

ciudad cuya expresión física y funcional la invade e integra, es decir, los espacios periurbanos son multifuncionales, ya que en ellos coexisten características y usos del suelo tanto citadino como rurales, sometidos a transformaciones de tipo social, físico y económico estrechamente vinculados a la enorme presencia del centro metropolitano. Por ello, es atinado encontrar términos asociados con diferentes matices: periferia, rururbano, suburbano, arrabal, entorno, extrarradio, suburbio, margen urbano, etc. Información especializada extraída del Glosario de Geografia en línea disponible en:

http:/club.telepolis.com/geografo/glosario/glosario.htm y de La Escuela Superior de Ciencias Experimentales y Tecnología (ESCET) de la Universidad Rey Juan Carlos de Madrid España, disponible en http://www.escet.urjc.es/ pad/WEB2005/DOCENCIA/EspaciosVerdes/espacioperiurbano.ppt

${ }^{12}$ Recomendamos la lectura diligente de las cuatro primeras páginas de Roberto Arlt. Su vida y su obra (2000) de Omar Borré en que traza un mapa de las calles por las que transitan los personajes de Arlt y el contexto en que se da su presencia en el lugar. 
escritura arltiana y que tan bien ha descrito la crítica tradicional de Roberto Arlt.

Los siete locos describe y provoca en el lector el mismo desconcierto que sienten los personajes en la acción de descubrimiento de su entorno. Creemos que se nos han revelado situaciones, hechos sin antecedentes previos. Remo descubre un espacio nunca visto por nadie, un no lugar que aún estando física y concretamente cerca ha sido invisibilizado por distintas razones, una de las cuales enunciamos: el virtual peligro que pudiera causar a la estabilidad del sistema que prescinde de esas zonas por no ser funcionales al principio de disciplinamiento de los cuerpos.

Los locos de Arlt "saben" y ven, llevan consigo un saber menor y ven lo que los "normales" de Buenos Aires no ven, y, más aún, reconocen en esos no lugares la potencia de la utopía y el cambio revolucionario. Claudia Gilman, en "Los siete locos: novela sospechosa de Roberto Arlt" (1993), señala:

... camina extrañado, como a través de una ciudad desconocida. Algunos techos, pintados de alquitrán, parecen tapaderas de ataúdes inmensos. En otros parajes, centelleantes lámparas eléctricas iluminan rectangulares ventanillas pintadas de ocre, de verde, de lila. En un paso a nivel rebrilla el cúbico farolito rojo que perfora con taladro bermejo la noche que va hacia los campos (83).

El campo, allá está el futuro del hombre, el reducto de la felicidad en que es posible experimentarse, donde la técnica es incipiente. La paradoja, eso sí, no se deja esperar. Los perturbadores contaminan este idílico territorio con el asentamiento de la sociedad secreta en Témperley, así como la sola concepción de la idea revolucionaria desestabiliza el equilibrio logrado por el territorio rural, aledaño a la urbe. Los locos no son capaces de darse cuenta de que están contaminando ese único espacio que es capaz de contenerlos, el espacio descubierto por ellos y en vías de destrucción por ellos mismos. Por medio de la mirada del angustiado Erdosain "surge un paisaje futurista que sacrifica el ayer y el hoy para un mañana de cálculos imposibles" (Kallinikos, 263).

\section{DESPLAZAMIENTO GEOGRÁFICO / METAFÓRICO}

Al salir de Buenos Aires, en el espacio que hemos llamado periurbano, el lector/personaje se enfrenta a un paisaje bastante cercano al de la ciudad, pero también con elementos del anillo siguiente: la pampa ${ }^{13}$. La zona periurbana, desolada y

\footnotetext{
${ }^{13}$ La literatura argentina, en el momento en que aparece Roberto Arlt, estaba pasando por un período bullente de reflexión acerca de los espacios naturales y el campo (indigenismo incluido), en el que sobresalen la figura de Ricardo Güiraldes (1886-1927) y Enrique Larreta (1875-1961). A propósito del carácter bucólico y pastoril de la literatura argentina a la llegada de Arlt, Raúl Larrea comenta: "Con el advenimiento de Roberto Arlt a nuestra literatura se opera un hecho incuestionable: frente a Güiraldes y a Larreta, novelistas recientes del campo argentino, venidos de la clase terrateniente, surge Arlt como novelista de ciudad, reflejando sus suburbios, sus tipos cosmopolitas y su lenguaje salpicado de dialectos extraños que dicen de otros cielos y otras tierras, e interpretando a uno de los sectores más humildes de la pequeña burguesía, con todos los síntomas de una aguda polarización" (Larra, 65).
} 
desagradable por su fealdad aparece básicamente en los trayectos de Erdosain entre la capital y Témperley y el trayecto a la casa de Los Espilas. En ambos casos podemos notar que este espacio "entre" aparece doblemente caracterizado; por un lado, exhibido como un espacio infernal y sombrío, y, por otro, como una zona que permite la transición geográfica y metafórica a un espacio signado por el principio de la esperanza.

La transición geográfica o material dice relación con el desplazamiento desde la "ciudad canalla", de la "vida puerca", al espacio bucólico y natural de la quinta de Témperley. Ahora, la transición metafórica señala el desplazamiento óptico desde la zona esperpéntica, en muchos casos amorfa, por la zona industrial posible sustentadora de la utopía, "no lugar" en que queden superados los estados de permanente angustia e infelicidad.

El capítulo I, subcapítulo XII, "Ser' a través de un crimen” se abre con la descripción nocturna de la estación de tren en Témperley

Un trozo de andén de la estación de Témperley estaba débilmente iluminado por la luz que salía de la puerta de la oficina de los telegrafistas. Erdosain sentóse en un banco junto a las palancas para los cambios de vías, en la oscuridad. Tenía frío y tal vez fiebre. Además, experimentaba la impresión de que la idea criminosa era la continuación de su cuerpo, como el hombre de tiniebla que pudiera arrojar en la luz. Un disco rojo brillaba al extremo del brazo invisible del semáforo; más allá otros círculos rojos y verdes estaban clavados en la oscuridad, ya la curva del riel galvanoplastiado de esas luces sumergía en las tinieblas su redondez azulenca o carminosa. A veces la luz roja o verde descendía.

Luego todo permanecía quieto, dejando de rechinar las cadenas en las roldanas y cesando el roce de los alambres en las piedras (Arlt, 77).

El tren es un "espacio otro", un "no lugar" diría Marc Augé (1993), un espacio de circulación que provee destinos en cuanto él mismo se desplaza a otra ubicación, emplazamiento de paso. Michel Foucault en Des espaces autres (1999) ${ }^{14}$, señala a propósito de la imagen del tren: "un tren es un extraordinario haz de relaciones, ya que es algo por donde se pasa, es igualmente algo por lo que se puede pasar de un punto a otro y luego, es también algo que pasa" (18). La estación de Témperley es un espacio que alterna su ubicación, que se fuga constantemente, mientras que la zona intermedia es un lugar que se distribuye de acuerdo con el distinto tipo de relaciones en una y otra ubicación geográfica. Remo navega en el ferrocarril desde la estación de Constitución y la estación de Témperley y es en este espacio móvil en que cavila la idea del secuestro de Barsut, acto con el que pretende vengar la humillación de que había sido objeto. El plan que maquina Erdosain lo hace sentir poderoso, ya que él y su idea andan circulando en desterritorializaciones y reterritorializaciones constantes, con lo que experimenta cierto placer sadomasoquista al considerar la posibilidad de "ser" mediante el crimen.

\footnotetext{
${ }^{14}$ Utilizamos la traducción de Marie Lourdes en Revista Versión. Estudios de Comunicación y Política, № 9, abril 1999, pp.15-26.
} 
El estatuto ontológico de los personajes arltianos permite, entre otras cosas, nombrarlos con cualquier palabra cargada con los semas de la inexistencia: loco, enfermo mental, revolucionario, salvaje, idiota, anarquista, imbécil, etc. Pero esta proposición tan inesperada como subversiva de ingresar al mundo de los visibles (normales), de los que "son", de los que "existen" y de los que "obran" con la negación misma del ser (la muerte), lleva consigo una revelación. Si la categoría de existente es proporcionada por un crimen, significa entonces que todos los "normales" son unos criminales y ellos (Erdosain, el Astrólogo, la Bizca...), los locos, no lo son porque no han matado a nadie... aún. El proyecto de convertirse en "seres" por medio de la muerte de otros seres anula la posibilidad de utopía.

Carlos Correas, en Arlt literato (1995), reflexiona sobre el "mal" en la novelística arltiana, a propósito de Los siete locos señala:

El contra-horror de la vida interior cernida por el mal es por lo pronto proyección de iniciativa. El "ser" a través de un crimen produce un ser de apariencia vertiginosa cuyo vaivén no debe detenerse; el mal "organiza" solo en tanto unidad negativa frente a la positividad dada: es unidad centrífuga que corroe el bien a partir de sí y que vuelve a sí en y por un continuo rechazo, pero que a la vez aspira a crear una afirmación ya no recibida sino puesta (157).

El acto criminal, su complejo e imbricado estatus, se concreta trayendo a Barsut desde Buenos Aires a Témperley. Esta es la primera fase de lo que podemos llamar rebelión personal de Erdosain quien desea venganza, con lo que podría acceder a una nueva forma de "ser" en el mundo, además de coincidir con el comienzo de los planes de rebelión de la sociedad secreta aglutinada alrededor de la figura del Astrólogo. En el viaje, víctima y victimario atraviesan la zona periurbana, uno al lado del otro en el ferrocarril. Remo mira por la ventana y percibe el paisaje como sigue:

Y sin embargo, todo continuaba lo mismo; el sol lucía allá en los campos; habíamos dejado atrás los frigoríficos, las fábricas de estearina y jabón, las fundiciones de vidrio y de hierro, los bretes con el vacuno oliendo los postes, las avenidas a pavimentar con sus llanuras manchadas de yeso y de surcos. Y ahora comenzaba, traspuesto Lanús, el siniestro espectáculo de Remedios de Escalada, monstruosos talleres de ladrillo rojo y sus bocazas negras, bajo cuyos arcos maniobraban las locomotoras, y a lo lejos, en las entrevías, se veían cuadrillas de desdichados, apaleando grava o transportando durmientes. Más allá, entre una raquítica vegetación de plátanos intoxicados por el hollín y los hedores de petróleo, cruzaba la senda oblicua de los chalets rojos para los empleados de la empresa, con sus jardincitos minúsculos, sus persianas ennegrecidas por el humo y los caminos sembrados de escoria y carbonilla (115-116).

El expresionismo de la escritura de Roberto Arlt conduce inexorablemente a la sombra del mundo interior del personaje. Remo, en sus momentos de desesperación y angustia, deambula por las calles de la ciudad como buscando algo que pudiera 
levantarlo de su agonía, pero en un medio con esas características es nula la posibilidad de iluminarse.

El tren eléctrico cruzaba ahora por Villa Luro. Entre montes de carbón y los gasómetros velados por la neblina relucían tristemente los arcos voltaicos. Grandes huecos negros se abrían en los galpones de las locomotoras, y las luces rojas y verdes, suspendidas irregularmente en la distancia, hacían más tétrica la llamada de las locomotoras (182).

Remo no solo camina por las calles trayectos cortos sino que también se monta en medios de transporte para recorrer distancias mayores como cuando se dirige al anillo exterior en un afán por salir del agobio y del abatimiento en que se encuentra. Recordemos que la noche anterior al crimen Remo sube a un tranvía que cruza toda la ciudad hasta llegar a las afueras de Buenos Aires, a un caserío llamado Ramos Mejía. Cuando el reloj de la estación marcaba las ocho de la noche, Erdosain bajó:

El tren se detuvo en Ramos Mejía. El reloj de la estación marcaba las ocho de la noche. Erdosain bajó.

Una neblina densa pesaba en las calles fangosas del pueblo.

Cuando se encontró solo en la calle Centenario, bloqueado de frente y las espaldas por dos murallas de neblina, recordó que al día siguiente asesinarían a Barsut. Era cierto, lo asesinarían. Hubiera querido tener un espejo frente a sus ojos para ver su cuerpo asesino, tan inverosímil le parecía ser el (el yo) que con tal crimen se iba a separar de todos los hombres (188).

A este otro espacio es llevado por su conciencia asesina. Aunque este viaje fuera de la ciudad tiene como objeto despejar su mente, lo que realmente ocurre es que el espacio oscuro y opaco, de escasa iluminación y que apenas deja entrever las fábricas y las calles desiertas, amplifica la tristeza y angustia existencial. Esa misma noche en casa de los Espila ${ }^{15}$ Erdosain es testigo de la materialización de uno de sus inventos: la rosa de cobre ${ }^{16}$ : "En el miserable cuchitril la maravillosa flor metálica exfoliaba sus pétalos bermejos" (192).

La "rosa de cobre" sintetiza ambas realidades en tensión: la tecnológica y la del sueño porvenir. La rosa, primera parte de esta imagen, remite al mundo campestre donde tranquilidad y belleza se conjugan de mejor manera. En cambio, el material en

\footnotetext{
${ }^{15}$ Los Espilas son los integrantes de una familia, como varias de Buenos Aires, que tuvo un pasado glorioso y lleno de esplendor en los negocios de orden industrial. Caídos en desgracia, ahora mismo viven en una fábrica abandonada donde se materializa el invento de Remo en que está cifrada su esperanza existencial. "Erdosain los observó compadecido. Hacía muchos años que conocía a los Espila. En otro tiempo la familia ocupaba una posición relativamente desahogada, luego una sucesión de desastres los había arrojado en plena miseria, y Erdosain, que encontró casualmente un día en la calle a Emilio, los visitó. Hacía siete años que no los veía y se asombró de reencontrarlos a todos viviendo en un cuchitril, ellos, que en otra época tenían criada, sala y antesala" (Arlt, 190).

${ }^{16}$ Recomendamos la lectura del apartado correspondiente en "'Habremos de reír, nos alegraremos, habrá deleite'. Reflexiones sobre la risa” (Segunda Parte), en Atenea, No 496, Segundo Semestre, 2009, pp. 11-40.
} 
que es confeccionada, el cobre, por supuesto, nos lleva al campo de la técnica desde donde reconocemos que es una materia de orden menor dentro de la escala de los metales. Este "símbolo de inocencia y de hermosura aparece alienado" (Kallinikos, 260) bajo la forma de una imagen sintética (rosa/cobre) que responde al mismo complejo panorama de contradicciones en que viven los integrantes de la sociedad secreta, en especial Erdosain.

Esta rosa tan especial se ennegrece porque esa es una cualidad propia del metal en que está fabricada, al parecer la revolución planificada por los locos de la inquietud revolucionaria participarán de la misma suerte. La bella "idea" del cambio social (la rosa) terminará como el cobre, deslucido y sin posibilidades ciertas de concreción, ya que todo aparece como una ilusión alimentada por la misma sociedad que genera o posibilita la conformación de grupos asociales. Jorge Rivera, en Roberto Arlt. Los siete locos, señala, a propósito de lo expuesto acerca de la rosa de cobre, que es "símbolo no del éxito ni de la salvación sino de la impotencia y la esperanza efimera" (62).

El episodio de la llegada de Remo a casa de los Espilas confirma una vez más el carácter paradójico del rol de la tecnología en la escritura de Los siete locos. Por un lado, la zona industrial genera polución, intoxica y contamina no solo las coordenadas geográficas de los personajes sino las coordenadas de su ser interior. Por el otro, Remo y el Astrólogo creen ciegamente en la ciencia y la tecnología como instrumentos para la revolución y el cambio social, el medio fundamental, la base del nuevo orden. La fábrica abandonada (el cuchitril) de los Espilas cifra no solamente la miseria y la muerte sino también la maravillosa curiosidad que significa la rosa, con ello esta zona periurbana industrial se asocia a la realización de los proyectos futuros señalados que, perfectamente, pueden ser funcionales a la transición necesaria hacia una nueva sociedad que, paradójicamente, no dista demasiado de la condición primaria de los personajes. No obstante, la tecnologización como principio para la sociedad secreta es una fuente de belleza, sueño y esperanza, apenas un haz de luz como este es necesario para salvarse de la miseria: "Soñaba enriquecerse con un descubrimiento. Su imaginación ocupaba las noches de máquinas extraordinarias, trozos incompletos de mecanismos girando sus engranajes lubrificados..." (Arlt, 207). Según Piglia, en cambio, inventar para Erdosain es "una operación demiúrgica destinada a encontrar la piedra filosofal moderna" (Piglia, Crítica y ficción, 27).

Por otro lado, Beatriz Sarlo, en el texto citado, piensa que el infierno científico y tecnológico es la única salida para abolir el orden social estático que impide incorporarse productivamente al torrente social como siquiera soñar la diferencia (61). La novela de Arlt agrega:

-Es necesario instalar fábricas de gases asfixiantes. Conseguirse químico. Células, en vez de automóviles camiones. Cubiertas macizas. Colonia de la cordillera, disparate. O no. Sí. No. 
También orilla Paraná una fábrica. Automóviles blindaje cromo acero níquel. Gases asfixiantes importantes. En la cordillera y en el Chaco estallar revolución. Donde haya prostíbulos, matar dueños. Banda de asesinos en aeroplano (230-231).

En la zona periurbana, en el anillo superior de la ciudad, en el margen vívido se sitúan los saberes sometidos cuyo fin es liberarse de esta condición mediante la articulación discursiva de sí que redunda en la conspiración y posterior conquista de la ciudad, el centro vital.

Hacer dinero con la adquisición de prostíbulos y por medio de la falsificación de divisas son formas concretas de implementación de la inquietud revolucionaria. Ambos proyectos van generando la ilusión de un porvenir iluminado, lejos del deterioro y decrepitud proyectados en Buenos Aires. Este espejismo permite a los personajes transgredir, traspasar los límites de la habitual angustia y la condición de seres residuales sin lugar ni ubicación en el plano urbano geográfico y metafórico de la urbe. La importancia del dinero es percibida intensamente por Piglia ${ }^{17}$, quien propone que la función del dinero en la novela de Arlt genera la ficción tal como la experiencia técnica puede generar inventos. En este sentido, existiría una equivalencia directa entre ficción y dinero porque ambos desacralizan el mundo: quien tiene dinero tiene el poder. En el mundo del relato la tarea de los personajes es confeccionar dinero en vez de ganarlo, actividad asociada a la falsificación y la estafa, ejes además de construcción del relato. "Identificado con la potencia y con la falsificación (el dinero) expresa, reprime, transforma y es el soporte de la ficción" (Piglia, La ficción del dinero, 80).

Con la exhibición del espacio bonaerense en Los siete locos y la insurrección de los perturbadores, el texto interroga no solo el futuro comunitario argentino sino también el futuro interior, personal e íntimo de aquellos sujetos que forman parte de este proceso complejo de crecimiento de la sociedad argentina a comienzos del siglo XX. El juguete rabioso, Los siete locos y Los lanzallamas van configurando una imagen anticipatoria del "escenario urbano porvenir" (Romano y Gel-Redman, 2000), en que la alienación social no es producida por una desconexión del sujeto con el mundo sino a su adaptación a las condiciones alienadas de la sociedad bonaerense por donde circulan. Dicho matiz sumado a las múltiples fracturas entre sujeto y medio van generando una ciudad alucinante, plagada de principios de posibilidad como de "no lugares" que reconstruyen desde el origen el eje organizador de los asentamientos humanos. La ciudad de Arlt es un centro sin centro. En este sentido, cierto sector de la crítica ha elaborado el concepto "profeta" para designar la capacidad anticipatoria de Arlt. El mismísimo Julio Cortázar ${ }^{18}$ lo considera uno "de nuestros videntes mayores", un iluminado que cuenta con el don

\footnotetext{
17 "Roberto Arlt: la ficción del dinero", en Roberto Arlt. Los siete locos / Los lanzallamas. Edición crítica de Mario Goloboff, Colección Archivos, Madrid, 2000.

18 "Prefacio. Apuntes de relectura", en Obra Completa de Roberto Arlt. 3 Vol. Buenos Aires, PlanetaCarlos Lohlé, 1991, pp. III-XI.
} 
de ver aquello que "los ojos de todos los días no saben ver" (Cortázar, VII). Ojos que, sin ninguna duda, comparte con sus personajes.

La dimensión utópica propuesta por Los siete locos es la de aquellos inconformes cuya angustia aparece como un sentimiento que nace de la imposibilidad de la adecuación a Buenos Aires, un territorio hostil, que favorece la exclusión y la marginalidad, pero que, sin embargo, encuentran en el camino de la revolución la herramienta para cambiar el mundo, para hacerlo más amigable, donde la angustia no sea la generadora de sujetos como ellos, y si fuera así, que aquellos no sean sistemáticamente expulsados. La geografia de la novela permite vislumbrar la decadencia y su influjo en los personajes quienes aparecen con su "yo dividido", diría el antipsiquiatra Ronald Laing (1988), sin embargo, en el texto también se perciben zonas "productivas" para el nuevo orden sustentador de la utopía: las zonas fuera de la ciudad, el campo, la tranquilidad y el sostén que la tierra puede dar. La probabilidad o no de la asunción de la revolución es casi anecdótica si pensamos que lo que importa es el proceso de búsqueda, el camino hacia un porvenir mejor, libre de las taras de la homogenización conductual, social, emocional, sexual, económica y cultural. Ante la comprensión de lo expuesto Roberto Arlt no deja de sorprendernos como historiador del presente y, por cierto, como "historiador del porvenir" (Piglia, Crítica y ficción, 38).

\author{
Universidad de Concepción* \\ Facultad de Humanidades y Arte \\ Departamento de Español \\ Casilla 160-C. Concepción (Chile) \\ jdcid@udec.cl
}

\title{
OBRAS CITADAS
}

Arlt, Roberto. Los siete locos. Buenos Aires: Losada, 1958.

Artaud, Antonin. Van Gogh el suicidado por la sociedad. Buenos Aires: Argonauta, 1994.

Augé, Marc. Los no-lugares. Espacios de anonimato. Una antropología de la sobremodernidad. Barcelona: Gedisa, 1993.

Bloch, Ernest. El principio esperanza. Valladolid: Trotta, 2004

Borré, Omar. Roberto Arlt. Su vida y su obra. Argentina: Planeta, 2000.

Correas, Carlos. Arlt literato. Argentina: Antuel, 1995.

Cortázar, Julio. "Prefacio. Apuntes de relectura", en Arlt, Roberto. Obra Completa de Roberto Arlt. 3 Vol. Buenos Aires: Planeta-Carlos Lohlé, pp. III-XI, 1991.

De Castro, Nea y González Bolaños, Aimée. "Centenario de Roberto Arlt, narrador de la marginalidad", en Islas 42: 3-12, 2000.

Deleuze, Gilles. Crítica y clínica. Barcelona: Anagrama, 1996.

Deleuze, Gilles y Guattari, Félix. Mil mesetas. Valencia: Pre-Textos, 2000.

Deleuze, Gilles y Parnet, Claire. Diálogos. Valencia: Pre-Textos, 1997.

Foucault, Michel. "De los espacios otros", en Revista Versión. Estudios de 
Comunicación y Política, № 9, abril 1999, pp. 15-26.

Gilman, Claudia. "Los siete locos: novela sospechosa de Roberto Arlt", en Cuadernos Hispanoamericanos. Los complementarios. Dedicado a Roberto Arlt, 11: 77-94, 1993.

Gostautas, Stasys. "La evasión de la ciudad en las novelas de Roberto Arlt", en Revista Iberoamericana, 80: 38, pp. 441-462, 1972.

Jitrik, Noé. "Presencia y vigencia de Roberto Arlt", en La vibración del presente. México: Fondo de Cultura Económica, 1987.

Kallinikos, Christinakomi. "Miradas entrecruzadas de espacios urbanos periféricos. Paisajes transitorios y transiciones narrativas en Los siete locos y Los lanzallamas", en Anales de Literatura Hispanoamericana. 31: 247-265, 2002.

Laing, Ronald. El yo dividido. México, Fondo de Cultura Económica, 1988.

Larra, Raúl. Roberto Arlt. El torturado. Buenos Aires: Ameghino Editora, 1998.

Le Corbusier. La ciudad del futuro. Buenos Aires: Ediciones Infinito, 2003.

Mandakovic, Ximena. "De la angustia a la revolución en "Los siete locos" y "Los lanzallamas". Seminario sobre Roberto Arlt. Poitiers: Centre de Recherches Latino-Américaines, 43-71, 1978.

Moreiras, Alberto. Tercer espacio: Literatura y duelo en América Latina. Santiago: ARCIS/LOM, 1999.

Onetti, Juan Carlos (1981) "Roberto Arlt", en El Juguete rabioso. Barcelona, Bruguera, pp. 7-16, 1981.

Pewzner, Evelyne. El hombre culpable. La locura y la falta en occidente. México: Fondo de Cultura Económica / Universidad de Guadalajara, 1999.

Piglia, Ricardo. "Roberto Arlt: la ficción del dinero", en Roberto Arlt. Los siete locos / Los lanzallamas. Edición crítica de Mario Goloboff. Madrid: Colección Archivos, 2000.

_Crítica y ficción. Buenos Aires: Seix Barral, 2000.

Rivera, Jorge. Roberto Arlt. Los siete locos. Buenos Aires: Hachette, 1981.

Romano, Evelia y Gel-Redman, Micah. "Profecías de entonces, textos de hoy: la ciudad y la narrativa argentina de las primeras y últimas décadas del siglo XX", en Revista de Humanidades: Tecnológico de Monterrey, 8: 197-220, 2000.

Sarlo, Beatriz. Una modernidad periférica: Buenos Aires 1920-1930. Buenos Aires: Nueva Visión, 1988.

Szmetan, Ricardo. "El centenario de Roberto Arlt. El mito del bárbaro y sus ecos", en Dramateatro Revista Digital, No 2, 2000, disponible en www.dramateatro.arts.ve/ensayos/n_0002/ecos.html. [13-11-2009]

Tassi, Loris. "Estética del fracaso en Roberto Arlt", en Cuadernos Hispanoamericanos 653-654: 167-178, 2004.

Torres Valenzuela, María. Roberto Arlt: El quinto fantoche. Tesis para optar al grado de Licenciado en Literatura. Santiago: Universidad de Chile, 2003. Disponible en http://www.cybertesis.cl/tesis/uchile/2003/torres_m/html/index-frames.html [8-04-2010] 